\section{NERS JOURNAL}

\section{AWAL BROS}

http://ojs.stikesawalbrosbatam.ac.id/index.php/Ners Journal

e-ISSN: 2721-6659

Kata kunci: Ketahanan Pangan Keluarga, Pengetahuan Ibu Tentang Grafik Pertumbuhan, status gizi baduta.

Korespondensi Penulis: darmin_dina@yahoo.co.id

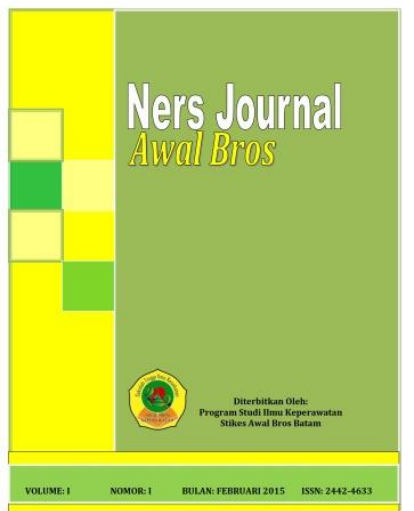

PENERBIT

Program Studi Ilmu Keperawatan STIKes Awal Bros Batam

Alamat: Jl. Abulyatama Kelurahan Belian Kecamatan Batam Kota, Kota Batam

\section{HUBUNGAN KETAHANAN PANGAN \\ KELUARGA DAN PENGETAHUAN IBU TENTANG GRAFIK PERTUMBUHAN TERHADAP STATUS GIZI BADUTA DI DESA PAMBOBORANG}

\author{
Darmin Diana ${ }^{1}$ \\ Prodi Diploma Kebidanan STIKES Bina Bangsa \\ Majene, Sulawesi Barat
}

Dikirim: 01/10/2020

Direvisi: $12 / 10 / 2020$

Disetujui: 31/10/2020

\begin{abstract}
ABSTRAK
Masa baduta merupakan masa emas atau window of opportunity,Usia ini sangat penting karena perkembangan dan pertumbuhan anak yang sangat pesat sehingga semua kebutuhan gizinya harus terpenuhi. Untuk mendapatkan generasi sehat dan kuat dan mewujudkan Indonesia prima, maka skala prioritas program ialah mulai anak masih dalam kandungan sampai berumur 2 tahun. Dalam memantau pertumbuhan anak telah hadir Kartu Menuju Sehat modifikasi dari WHO-NCHS dan wajib dimiliki oleh semua balita. Tujuan penelitian ini adalah untuk mengetahui hubungan ketahanan pangan keluarga dan pengetahuan ibu tentang grafik pertumbuhan terhadap status gizi baduta di Desa Pamboborang Kabupaten Majene. Penelitian ini merupakan penelitian kuantitatif dengan pendekatan Cross Sectional. Populasi penelitian adalah seluruh baduta di Desa Pamboborang. Sampel penelitian sebanyak 40 responden dengan menggunakan purposif sampling dan instrumen yang digunakan adalah kuesioner. Tekhnik analisa data menggunakan Uji Statistik Chi square dengan nilai $\alpha=$ 0,05 . Hasil penelitian menunjukkan bahwa terdapat hubungan antar ketahanan pangan keluarga terhadap status gizi baduta dengan $\mathrm{p}=0,042<\alpha=0,05$, tidak ada hubungan antara pengetahuan ibu tentang grafik pertumbuhan terhadap status gizi baduta dengan nilai $p=1>\alpha=0,05$. Sehingga disimpulkan terdapat hubungan antara ketahanan pangan keluarga terhadap status gizi dan tidak terdapat hubungan antara pengetahuan ibu tentang grafik pertumbuhan terhadap status gizi baduta. Sehingga disarankan kepada para ibu baduta agar selalu memperhatikan asupan makanan yang baik dan rutin ke posyandu agar dapat diketahui perkembangan status gizi balitanya.
\end{abstract}




\section{PENDAHULUAN}

Status gizi didefenisikan sebagai status kesehatan yang dihasilkan oleh keseimbangan antara kebutuhan nutrisi dan jumlah asupan nutrisi untuk berbagai fungsi biologis, fisik, perkembagan, aktifitas, pemeliharaan kesehatan dan lainnya. Status gizi dapat pula diartikan sebagai gambaran kondisi fisik seseorang sebagai refleksi dari keseimbangan energy yang masuk dan yang dikeluarkan oleh tubuh (Marmi, 2013).

Masa Baduta merupakan masa yang memerlukan perhatian khusus, karena pada masa ini terdapat pertumbuhan dan perkembangan yang sangat pesat. Masa ini juga termasuk masa yang rawan terhadap penyakit, sehingga peran keluarga, terutama ibu sangat dominan. Untuk memonitor pertumbuhan Balita secara cermat, maka dapat digunakan Kartu Menuju Sehat (KMS) (Arisman, 2007).

Masa baduta (bawah dua tahun) merupakan "Window of opportunity". Pada masa ini, seorang anak memerlukan asupan zat gizi yang seimbang baik dari segi jumlah maupun proporsinya untuk mencapai berat dan tinggi badan yang optimal (Soeparmanto dalam Putri, 2008).

Faktor yang memengaruhi tumbuh kembang anak terdiri atas sebab langsung dan tak langsung. Sebab langsung meliputi kecukupan pangan dan keadaan kesehatan, sedangkan sebab tak langsung meliputi ketahanan pangan keluarga, pola pengasuhan ibu, pemanfaatan pelayanan kesehatan, dan sanitasi lingkungan.

Rumah tangga yang mengalami rawan pangan di Indonesia sebesar 30\%, sedangkan sangat rawan sebesar $11 \%$.Ketahanan pangan erat kaitannya dengan masalah gizi. Prevalensi balita mengalami gizi kurang pada tahun 2007 di Indonesia sebesar 19,6\%, menurun menjadi 18,4\% tahun 2010, namun meningkat menjadi 19,6\% tahun 2013 (RISKESDAS, 2013)

Konsumsi pangan penduduk Indonesia juga mengalami fluktuasi dari tahun 2012, 2013 dan 2014. Tahun 2012 sebesar 1945 kkal/kap/hari menurun menjadi 1931 kkal/kap/hari (2013) kemudian meningkat menjadi 1949 kkal/kap/hari (2014). Konsumsi pangan yang tidak memenuhi standar selain menyebabkan masalah rawan pangan di wilayah juga mempengaruhi terhadap status gizi khususnya balita yang merupakan kelompok rawan (Vulnerable group). Rawan pangan dan rawan gizi pada dasarnya merupakan gambaran dari situasi kecukupan pangan dan status gizi individu pada kelompok atau komunitas masyarakat disuatu wilayah. Penelitian serupa menunjukkan jumlah penduduk Indonesia rumah tangga yang mengalami rawan pangan di Indonesia sebesar $30 \% \quad(33 \%$ di perdesaan dan $27 \%$ di perkotaan). Penelitian lain menyebutkan rumah tangga termasuk kategori sangat rawan pangan sekitar 25,1 juta orang $(11,1 \%)$.

Pengetahuan ibu balita mengenai KMS dapat berpengaruh pada status gizi baduta. Ibu baduta yang tahu tentang arti grafik dalam KMS sebanyak $18 \%$, yang tahu tentang pesan 
imunisasi sebanyak $29 \%$, dan tahu tentang pesan diare sebanyak 58\%, sedangkan yang tahu tentang jenis makanan yang harus diberikan sesuai umur anak sebanyak $61,3 \%$. KMS sebagai sumber informasi pemberian makan balita, imunisasi dan diare hanya dilakukan $16 \%$ oleh ibu balita (Pusat Penelitian dan Pengembangan Depkes RI, 2001)

\section{METODE PENELITIAN}

Penelitian dilaksanakan di Desa Pambo borang yang merupakan salah satu wilayah kerja Puskesmas Totoli. Puskesmas Totoli memiliki wilayah kerja 3 Desa dan 2 Kelurahan.

Desa Pamboborang terdiri dari 5 Dusun Dengan wilayah kerja pelaksanaan Posyandu terdiri atas tiga wilayah kerja.

Jenis penelitian yang digunakan adalah kuantitatif dengan desain analitis, untuk mengetahui hubungan variabel-variabel yang di teliti dengan pendekatanCross Sectional dengan menggunakan uji chi square untuk mengetahui hubungan ketahanan pangan dan pengetahuan ibu membaca grafik pertumbuhan (KMS) dengan status gizi baduta di Desa Pamboborang Kabupaten Majene.

\section{Populasi dan Sampel}

Populasi dalam penelitian ini adalah seluruh baduta usia $6-24$ bulan yang bertempat tinggal di Desa Pamboborang Kabupaten Majene. Sampel pada penelitian ini adalah baduta usia $6-24$ bulan. Teknik pengambilan sampelyaitu purposif sampling dengan pertimbangan sebagai berikut :Ibu yang memiliki baduta umur 6 - 24 bulan, Ibu baduta bersedia menjadi responden, Ibu baduta yang ada pada saat penelitian

\section{Pengumpulan Data}

Jenis data yang digunakan adalah data primer yaitu dengan mengumpulkan data kusioner dari responden atau ketika memeriksa lembar observasi. Periksa kembali apakah ada jawaban responden yang ganda atau belum dijawab. Jika ada, sampaikan kepada responden untuk diisi atau diperbaiki.

\section{Analisis Data}

Analisis bivariat yang digunakan dalam penelitian ini yaitu uji Chi Square dengan nilai $\alpha=5 \%$ dengan menggunakan program SPSS untuk mengetahui ada tidaknya hubungan ketahanan pangan dengan status gizi indeks $\mathrm{BB} / \mathrm{U}$ dan pengetahuan ibu dengan status gizi indeks $\mathrm{BB} / \mathrm{U}$ pada baduta.

\section{HASIL DAN PEMBAHASAN}

Hasil penelitian dengan uji statistik chi square dengan nilai $\mathrm{p}=0,042$ dengan taraf signifikan $\alpha=0,05$ membuktikan nilai $\mathrm{p}<\alpha$ atau $\mathrm{Ha}$ diterima Ho ditolak. Maka secara statistik dinyatakan ada hubungan antara ketahanan pangan terhadap status gizi baduta. Dalam penelitian ini didapatkan keluarga tahan pangan namun memiliki baduta dengan status gizi baik $69,7 \%$ lebih banyak, hal ini dapat terjadi melihat serangkaian pertanyaan dalam kuesioner bisa menimbulkan kesalah pahaman bagi responden. Tidak sedikit responden yang mengira bahwa pendataan yang dilakukan peneliti merupakan program desa akan adanya bantuan bagi keluarga kurang mampu yang memiliki baduta, walaupun peneliti sudah memberikan penjelasan tujuan penelitian yang dilakukan.

Hasil penelitian pengetahuan ibu tentang grafik pertumbuhan terhadap status gizi baduta disimpulkan bahwa tidak ada hubungan yang bermakna. Hal tersebut dapat terjadi mengingat bahwa status gizi baduta penyebabnya multikompleks yang tidak dapat diukur dari satu faktor saja. Pola konsumsi makanan dan keadaan kesehatan anak merupakan faktor secara langsung 
mempengaruhi status gizi anak.

Penelitian ini sejalan dengan hasil penelitian yang dilakukan oleh Mastari (2009) dengan judul "Hubungan Pengetahuan Ibu Balita Dalam Membaca Grafik Pertumbuhan KMS Terhadap Status Gizi Balita". Hal ini disebabkan karena status gizi multifaktor atau tidak dipengaruhi satu faktor saja. Melainkan dapat dipengaruhi oleh faktor lain seperti pendapatan keluarga, pendidikan ibu, akses pelayanan kesehatan, ketahanan pangan dan pola makan.

\section{KESIMPULAN}

Ada hubungan ketahanan pangan keluarga terhadap status gizi baduta di Desa Pamboborang Kecamatan Banggae Kabupaten Majene tahun 2018. Tidak Ada hubungan pengetahuan ibu membaca grafik pertumbuhan terhadap status gizi di Desa Pamboborang Kecamatan Banggae Kabupaten Majene tahun 2018. Adapun saran yang bias diberikan Peningkatan pembinaan kader Posyandu yang merupakan ujung tombak penyuluhan pemanfaatan KMS sebagai pedoman pemantauan status gizi baduta.

Terus meningkatkan penyuluhan kesehatan menyangkut perihal zat gizi yang mempengaruhi status gizi dan memotivasi ibu duta untuk tetap ikut serta dalam kegiatan penimbangan. Menggerakkan ibu - ibu dalam memanfaatkan lahan kosong menjadi pasar dekat dalam arti menanam berbagai sayuran sebagai upaya dalam menambah persediaan pangan keluarga untuk mencegah gizi kurang akibat ketahanan pangan keluarga yang minim.

\section{DAFTAR PUSTAKA}

Astutik. 2014. Hubungan antara ketahanan pangan rumah tangga dengan status gizi anak balita di wilayah kerja puskesmas talang kabupaten pamekasan 2014.

Depkes RI. 2010. Badan penelitian dan pengembangan kesehatan. Jakarta.

Dinkes Kab. Majene. 2014-2016. Profil dan laporan tahunan dinas kesehatan
Kabupaten majene. Majene: tidak diterbitkan.

Dinkes Provinsi Sulawesi Barat. 2012.

Profil dinas kesehatan sulawesi barat. Sulaweis barata: tidak diterbitkan

Herman, erni. 2016. Hubungan pengetahuan dan pola asuh ibu dengan status gizi balita di Puskesmas Sendana $1 \mathrm{Kec}$. Sendana Kab. Majene. (skripsi tidak diterbitkan) STIKES Bina Bangsa Majene 2016.

Jayarni dkk. (2018). Hubungan Ketahanan Pangan Dan Karakterisitik Keluarga Dengan Status Gizi Balita Usia 2-5 Tahun, (journal.unair. ac.id)

Josephine ruth, dkk. Faktor-faktor sosial ekonomi masyarakat terhadap ketahanan pangan rumah tangga di medan, [online], (journal. agribisnis fakultas pertanian USU ac.id)

Kemenkes RI. 2017.Buku saku pemantauan status gizi 2017.

Kemenkes RI. 2011. Standar Antropometri Penilaian Status Gizi Anak. Jakarta: Direktorat Bina Gizi; 2011.

Khairiyah oktarisa, kusuma puspita (2016). Faktor-faktor yang mempenagruhi pengetahuan orang tua mengenai kelainan genetik disabilitas intelektuak di semarang, [online]

Meiranny, arum. 2017. Pengetahuan ibu tentang kartu menuju sehat (KMS) mempengaruhi pertumbuhabn balita.

Pristiani E, Junaid, Paridah (2016). Hubungan Pengetahuan, Sikap, Dan Status Pekerjaan Ibu Balita Dengan Frekuensi Penimbangan Balita Ke Posyandu Di Wilayah Kerja Puskesmas Pamandati Kabupaten Konawe Selatan. Fakultas Kesehatan Masyarakat Universitas Halu Oleo. unsubmitted.

RI D (2009). Pedoman Penggunaan Kartu Menuju 
Sehat (KMS) Balita. Jakarta:

Departemen Kesehatan RI.

Roseliana. Gambaran pengetahuan ibu tentang kartu menuju sehat,

repository,uinjkt.ac.id

Sri, mila w. 2012. Faktor-faktor yang mempengaruhi status gizi balita di rw 06 kelurahan pancoran mas kecamatan pancoran mas-depok. Depok: fakultas ilmu keperawatan universitas indonesia.

Wahab, abdul. 2013. Pengantar Riset Bidang

Kesehatan Dan Keperawatan

Yogyakarta. Kaukaba Dipantara 